Revisión bibliográfica

Volumen 30(3):899-915. Septiembre-diciembre, 2019

e-ISSN 2215-3608, doi:10.15517/am.v30i3.35136

http://www.revistas.ucr.ac.cr/index.php/agromeso

\title{
Arbustivas forrajeras: importancia en las ganaderías de trópico bajo Colombiano $^{1}$
}

\section{Fodder shrubs: relevance in cattle systems of Colombian low altitude lands}

\author{
Jeraldyn Argüello-Rangel ${ }^{2}$,Liliana Mahecha-Ledesma², Joaquín Angulo-Arizala²
}

1 Recepción: 14 de noviembre, 2018. Aceptación: 11 de marzo, 2019. El trabajo formó parte de la tesis de la Maestría en Ciencias Animales de la primera autora "Uso de arbustivas forrajeras en la cría y levante de ganado BON x Cebú en Caucasia, Antioquia". Universidad de Antioquia, Facultad de Ciencias Agrarias. Medellín, Colombia.

2 Universidad de Antioquia, Facultad de Ciencias Agrarias, Grupo de Investigación en Ciencias Agrarias (GRICA). AA1126, Ciudadela Robledo, Cra 75 No 65-87. Medellín, Colombia. Teléfono +5742199147. jeraldynarguellorangel@gmail.com; liliana.mahecha@udea.edu.co (autor para correspondencia; http://orcid.org/0000-0003-3377-8399); joaquin.angulo@udea.edu.co

\section{Resumen}

Introducción. Las ganaderías de trópico bajo enfrentan el desafío de adaptar sus producciones a las consecuencias del cambio climático, que ha generado épocas secas prolongadas y escasez de alimento para los animales en estos periodos. Objetivo. El objetivo de esta revisión bibliográfica fue recopilar y analizar resultados de investigaciones sobre las especies forrajeras arbustivas: Tithonia diversifolia, Gliricidia sepium, Cratylia argentea y Crescentia cujete, como estrategia para mejorar la oferta nutricional en las ganaderías en trópico bajo. Desarrollo. En Colombia, las ganaderías de carne se localizan principalmente en trópico bajo, y suelen tener problemas de alimentación por la pobre calidad de las pasturas y su baja disponibilidad en la época seca. Los sistemas silvopastoriles (SSP) contribuyen a mejorar los indicadores productivos y reproductivos de los animales, ya que integran en diferentes arreglos y estratos, plantas leñosas perennes (árboles y/o arbustivas), leguminosas (rastreras, arbustivas) y pasturas, con una mayor oferta nutricional y forrajera que los sistemas convencionales. Las arbustivas T. diverfisolia, G. sepium, C. argentea, y C. cujete, por sus características multipropósito, producción de biomasa y adaptación a distintas condiciones climáticas y edáficas, han sido usadas en ramoneo, bancos forrajeros, cercas vivas y conservación de forrajes, p. ej. ensilaje. Conclusión. Por sus características, usos, producción de biomasa y perfil nutricional, sería pertinente evaluar el comportamiento de estas especies en estrategias de alimentación en ganaderías en condiciones de trópico bajo.

Palabras clave: Gliricidia sepium, Cratylia argentea, Crescentia cujete, sistemas silvopastoriles, Tithonia diversifolia.

\begin{abstract}
Introduction. Low tropics lands cattle, face the challenge to adapt the production systems to the climate change consequences, wich has generated longer dry seasons and more food shortage for the animals during these periods. Objective. The objective of this literature review was to collect and analyze research results on shrubs forage
\end{abstract}


species Tithonia diverfisolia, Gliricidia sepium, Cratylia argentea, and Crescentia cujete as a strategy to improve the nutritional offer in livestock in the low tropics. Development. In Colombia, beef cattle production is mainly located in the low tropics, and usually have feeding problems due to poor grasses quality and low availability in drought period. Silvopastoral systems (SSP) contribute to improve the productive and reproductive performance of cattle, since they integrate trees and/or shrubs, and grasses, combining diverse forage strata, with a greater nutritional and forage offer than conventional systems. The shrubs $T$. diverfisolia, G. sepium, C. argentea, y C. cujete due to their multipurpose characteristics, biomass production, and adaptation to diverse climatic and edaphic conditions, have been used in grazing, fodder banks, live fences and forage conservation, e.g. silage. Conclusion. Due to their characteristics, uses, biomass production, and nutritional profile, it would be pertinent to evaluate the behavior of these species in feeding strategies in cattle farms under tropics conditions.

Keywords: Gliricidia sepium, Cratylia argéntea, Crescentia cujete, silvopastoral systems, Tithonia diversifolia.

\section{Introducción}

En Colombia, la producción de carne (cría, levante, ceba) bovina se localiza principalmente en las regiones de trópico bajo (0 a1000 msnm), donde es común encontrar carencias en la alimentación de rumiantes por la baja relación de energía: proteína de las pasturas, y la baja disponibilidad de alimento en época seca (Sossa y Barahona, 2015; Sotelo et al., 2017).

La ganadería tradicional ha sido afectada productiva y económicamente por el recrudecimiento de sequías y lluvias ocasionado por el cambio climático (Tapasco et al., 2015). Este efecto se relaciona con la baja capacidad de resiliencia de los sistemas, debido al bajo nivel de tecnificación, al limitado acceso a modelos productivos sostenibles, inadecuado asesoramiento técnico y mala oferta nutricional (Barahona et al., 2014).

En trópico bajo, es común hallar ganaderías con baja tecnificación, inadecuado manejo de praderas, y una carga animal que en sistemas extractivos y extensivos no supera 1 animal ha' ${ }^{-1}$ Mahecha, 2002) o 0,6 UUG ha-1 (FEDEGAN, 2006). Estos sistemas exhiben también, deficiencias en materia de acompañamiento técnico, bajas ganancias de peso de 250 a $350 \mathrm{~g}_{\text {animal }}{ }^{-1}$ día $^{-1}$, pesos al destete de 140 a $150 \mathrm{~kg}$ y bajos indicadores reproductivos con intervalo entre partos de 23 meses y un porcentaje de natalidad del $54 \%$ (Mahecha, 2002; Tapasco et al., 2015; Botero y Martínez, 2017). Debido a esta problemática, es pertinente buscar alternativas que favorezcan la productividad y sean afines a los conceptos de sostenibilidad ambiental y conservación de la biodiversidad (Bacab et al., 2013; Gaviria-Uribe et al., 2015; Murgueitio et al., 2016; Navas, 2017).

Una de las alternativas para mejorar la capacidad de resiliencia en los sistemas ganaderos en épocas críticas, es la implementación de sistemas silvopastoriles (SSP). Los SSP integran plantas leñosas perennes (árboles y/o arbustivas), leguminosas (rastreras, arbustivas) y pasturas, en diferentes tipos de arreglos, tales como potreros, bancos de proteína, cercas vivas (Murgueitio et al., 2011; Sotelo et al., 2017). Los estudios en SSP han hallado, que contribuyen a mejorar la oferta forrajera, las propiedades de los suelos, la actividad biológica de micro y macro fauna, el control de la erosión y escorrentía, entre otros (Bacab et al., 2013; Gaviria-Uribe et al., 2015; Sotelo et al., 2017).

Entre las especies que, por su adaptación a diversas condiciones edafoclimáticas y uso multipropósito, pueden ser útiles en la ganadería, están el botón de oro (Tithonia diversifolia Hemsl A. Gray) (Castañeda et al., 2016), el matarratón (Gliricidia sepium Jacq.) (Arango et al., 2016), la cratylia (Cratylia argentea O. Kuntze) (Sotelo et al., 2017) y el totumo (Crescentia cujete L.) (Gómez et al., 2015). El uso de estas especies en suelos de baja fertilidad, favorecería la fijación de fósforo, como es el caso del botón de oro (Pérez et al., 2009; Gallego-Castro et al., 2014) o del matarratón y la cratylia que fijan del nitrógeno (Lascano et al., 2002; Arango et al., 2016). De igual forma, se 
ha encontrado que el botón de oro y el matarratón son útiles en la recuperación y/o protección de los suelos (Ferreira et al., 2016; Sotelo et al., 2017). El objetivo de la presente revisión bibliográfica fue recopilar y analizar resultados de investigaciones sobre las especies forrajeras arbustivas: T. diverfisolia, G. sepium, C. argentea y C. cujete, como estrategia para mejorar la oferta nutricional en las ganaderías en condiciones de trópico bajo.

\section{Características generales de especies arbustivas con uso potencial en alimentación ani- mal en trópico bajo}

El botón de oro (T. diversifolia), el matarratón (G. sepium), la cratylia (C. argentea), y el totumo (C. cujete), son especies taxonómicamente diferentes. El botón de oro es una Asteracea (Castañeda et al., 2016), el matarratón y la cratylia son de la familia Fabaceae (Chaverri y Cicció, 2015; Sotelo et al., 2017), y el totumo es una Bignoniaceae (Calle et al., 2011a). Estas especies poseen hábitos de crecimiento asociados al manejo aplicado; la cratylia y el botón de oro son arbustos, en tanto que el matarratón y el totumo son especies, a los que si se les aplica un manejo de poda frecuente, se puede maximizar el aprovechamiento de su biomasa, como arbustivas (Cuadro 1).

Cuadro 1. Características y adaptabilidad de las especies T. diversifolia, G. sepium, C. argentea y C. cujete, reportadas por diversos autores. Colombia. 2018.

Table 1. Characteristics and adaptability of the species T. diversifolia, G. sepium, C. argentea, and C. cujete, reported by several authors. Colombia. 2018.

\begin{tabular}{|c|c|c|c|c|}
\hline Especie & Altitud msnm & $\begin{array}{c}\text { Precipitación } \\
\text { mm año-1 }\end{array}$ & Condiciones suelos & Referencia \\
\hline T. diversifolia & $0-2400$ & $800-5000$ & $\begin{array}{l}\text { Suelos bien drenados } \\
\text { Fertilidad variable }\end{array}$ & $\begin{array}{l}\text { Gallego-Castro et al. (2014); } \\
\text { Mejía-Díaz et al. (2017) }\end{array}$ \\
\hline G. sepium & $0-1600$ & $600-3000$ & $\begin{array}{l}\text { No tolera altas concentraciones de } \\
\text { aluminio } \\
\text { Se da en sitios erosionados } \\
\text { Fija nitrógeno } \\
\text { Suelos bien drenados } \\
\text { Fertilidad variable }\end{array}$ & $\begin{array}{l}\text { López (2005); Cuervo- } \\
\text { Jiménez et al. (2013); } \\
\text { Chaverri y Cicció (2015); } \\
\text { Castañeda et al. (2016). }\end{array}$ \\
\hline C. argentea & $0-1200$ & $900-4000$ & $\begin{array}{l}\text { Profundos, tolera altas concentraciones de } \\
\text { aluminio } \\
\text { Suelos bien drenados } \\
\text { Fertilidad variable }\end{array}$ & $\begin{array}{l}\text { Lascano et al. (2002); } \\
\text { Arango et al. (2016); Sotelo } \\
\text { et al. (2017). }\end{array}$ \\
\hline C. cujete & $0-1500$ & $1150-7500$ & $\begin{array}{l}\text { Fertilidad variable } \\
\text { Tolera drenaje deficiente }\end{array}$ & $\begin{array}{l}\text { Rodríguez y Roncallo et al. } \\
\text { (2013); Gómez et al. (2015). }\end{array}$ \\
\hline
\end{tabular}

En cuanto a su distribución geográfica y adaptabilidad, se pueden hallar en un amplio rango de pisos térmicos y pueden sobrevivir en condiciones variables de pluviosidad, destacándose el totumo (C. cujete) (Arango et al., 2009; Calle et al., 2011b) y la cratylia (C. argentea) (Lascano et al., 2002; Sotelo et al., 2017), por su tolerancia a la sequía (Cuadro 1). De igual modo, toleran una moderada a baja exposición a sombra, suelos con pH ácido, baja disponilidad de nutrientes, baja fertilidad y altas saturaciones de aluminio, aunque, cabe resaltar que, el botón de oro, la cratylia y el matarratón, prefieren suelos bien drenados, en comparación con el totumo, que puede tolerar suelos con drenaje regular (Lascano et al., 2002; Calle et al., 2011a; Cuervo-Jiménez et al., 2013; Gallego-Castro et al., 2014; Gómez et al., 2015). Destaca el totumo además, por su amplia distribución en el territorio colombiano y alta plastacidad, con amplia presencia en la región Caribe y una disminución hacia los ecosistemas de tipo andino. Se ha identificado 
en total 56 accesiones de germoplasma en las regiones Amazonía, Caribe, Pacífico, Orinoco y Andes, con una significativa diversidad fenotípica del fruto, reflejada en la variabilidad de formas y tamaños (Arango et al., 2009).

\section{Usos de las especies arbustivas}

El potencial del botón de oro en alimentación de rumiantes se debe al alto nivel de proteína, que puede variar entre 13,3 y 28,7 \% (Verdecia et al., 2011; Gallego-Castro et al., 2017), similar al de las leguminosas, una producción de biomasa entre 17,6 y 24,7 t ha-1 (Ferreira et al., 2016, Gallego, 2016), niveles significativos de fósforo que pueden variar de 0,27 a $0,28 \%$ (Ruiz et al., 2017), carbohidratos no estructurales con un 7,8 a 18,41 $\%$ (Medina et al., 2009; Gallego-Castro et al., 2017), una alta digestibilidad entre 75,2 y 78,5\% (Verdecia et al., 2011) y una rápida recuperación (rebrote), este último rasgo es el que permite su uso para ramoneo (Mejía-Díaz et al., 2017; Ruiz et al., 2017). La T. diversifolia, se ha empleado en alimentación animal de rumiantes (bovinos, ovinos) y monogástricos (conejos, cerdos) en diferentes presentaciones (fresca, ensilada y en harinas) (Gutiérrez et al., 2017; Savón et al., 2017). Para rumiantes se ha implementado diversas formas de establecimiento, como el arreglo espacial en potreros (ramoneo), en bancos de proteína para corte y acarreo, para elaboración de ensilajes (solos o mixtos), harinas, entre otros (Ruiz et al., 2017; García et al., 2017).

Entre las propiedades atribuidas a la $T$. diversifolia está la capacidad de mejorar las características edáficas (biológicas y físicas) cuando se utiliza como abono orgánico, puesto que aporta nutrientes como fósforo, nitrógeno y potasio presentes en sus hojas (Ojeniyi et al., 2012; Ruiz et al., 2014; Fungo et al., 2017; Moriones y Montes, 2017; Ruiz et al., 2017). De igual manera, se ha utilizado como repelente natural contra hormigas cortadoras de hojas (Atta cephalotes) (Calle y Murgueitio, 2008), en restauración ecológica, en apicultura por su aptitud melífera (fuente de néctar y polen) (Ríos y Salazar, 1995; Calle y Murgueitio, 2008) y recientemente se evaluó como biocombustible (biogas) (Dahunsi et al., 2017). Con relación al matarratón (G. sepium) y la cratylia (C. argentea), por ser leguminosas, tienen la habilidad de fijar nitrógeno, debido a la relación simbiótica establecida en la raíz con bacterias del género Rhizobium a través de la formación de nódulos (Lascano et al, 2002; Cubillos-Hinojosa et al., 2011; Gei y Powers, 2015). En el caso de la cratylia, se ha usado en alimentación animal en corte y acarreo -previo secado-henificación, y ensilaje (Arango et al., 2016; Sotelo et al., 2017; Valles-de-la-Mora et al., 2018).

El matarratón, además de usarse en alimentación animal (Chaverri y Cicció, 2015), tiene propiedades melíferas (Fonte et al., 2013), se puede aprovechar su madera para leña, en sistemas silvopastoriles sirve para cercas vivas y/o sombra (Calle y Murgueitio, 2007), y en arreglos agroforestales se ha establecido en asocio con café o cacao (Hosseini et al., 2017). El matarratón ha sido establecido también, asociado a cultivos de maíz en modelos agroforestales en Kenia, África, para mejorar la fertilización del cultivo, atribuyéndosele además, la propiedad de favorecer el aprovechamiento del agua del suelo por parte del cultivo de maíz (Smethursta et al., 2017). En cuanto al totumo ( $C$. cujete), en la costa Caribe colombiana, se ha utilizado en alimentación de rumiantes, a partir de la elaboración de ensilaje salino de la pulpa del fruto (Calle et al., 2011a; Flórez, 2012), y en sistemas silvopastoriles como arbusto para ramoneo (Rodríguez y Roncallo, 2013; Barragán, 2013). El totumo sirve también para la elaboración de artesanías a partir del fruto, para leña e incluso con fines ornamentales (Gómez et al., 2015).

\section{Características agronómicas}

En lo que respecta a las características agronómicas, el matarratón, el botón de oro, y el totumo, pueden reproducirse por semilla sexual y por material vegetal (López, 2005; Gallego, 2016, Saavedra, 2016; Gómez et al., 2015), mientras que de la cratylia solo se conoce su reproducción de forma sexual (Lascano et al., 2002). El botón de oro, tanto en bancos forrajeros como en ramoneo (método alimenticio para obtener las hojas, flores o frutos de 
plantas que se encuentran en las ramas de los árboles o arbustos), puede sembrarse por estaca o por semilla, según la disponibilidad del material (Castañeda et al., 2016; Gallego, 2016).

La siembra por estaca presenta desventajas, producto de los costos de establecimiento, la mano de obra y los cuidados rigurosos para conservar su viabilidad (por deshidratación), además de que el sistema radicular que se desarrolla a partir de la estaca no posee una raíz principal fuerte, comparado con plantas establecidas a partir de semilla sexual. Pese a ello, el método más difundido en la actualidad es la siembra por estaca, ya que la que la siembra por semilla sexual es una alternativa recientemente evaluada, que requiere de mayores estudios que aseguren un mejor porcentaje de germinación y protocolos de establecimiento en campo (Gallego, 2016; Saavedra, 2016; Gallego-Castro et al., 2017; Londoño et al., 2019).

Los estudios en materia de propagación de botón de oro por semilla sexual, han estado orientados a la fenología de la especie (Saavedra, 2016), así como al análisis agronómico y productivo de la misma, en aspectos como el redimiento forrajero y la composición bromatológica (Gallego, 2016); bajo este esquema, se evaluó tres métodos de siembra: por estaca (Pes), semilla sexual con manejo in vitro (Piv) y semilla sexual con manejo por almácigos (Psx). El método de siembra no afectó la composición nutricional y la producción de biomasa, tampoco que la germinación puede darse entre los siete y dieciséis días; haciendo de la semilla sexual un método efectivo para establecer botón de oro (Gallego-Castro et al., 2017).

En cuanto a los tiempos de establecimiento, en sistemas silvopastoriles intensivos (SSPi) de trópico medio y bajo, el botón de oro requiere, de seis a siete meses para realizar el primer pastoreo, con periodos de ocupación no superiores a los dos días (Solarte et al., 2013), y entre 60 a 90 días de descanso teniendo en cuenta si es época seca o lluviosa (Alonso et al., 2013; Ruiz et al., 2014; Mejía-Díaz et al., 2017). En bancos forrajeros la edad del primer corte se estima a los cuatro meses, con cortes sucesivos cada 60 días a $40 \mathrm{~cm}$ de altura, y producción promedio de 9,1 t ha-1 MS (Holguín et al., 2015). La edad entre cortes puede variar dependiendo de las características edafoclimáticas de la zona; se ha aplicado a edades de 49-50 días en el Valle del Cauca, Colombia (Ríos y Salazar, 1995), 60 días en época lluviosa, 80 días en época seca en Cuba (Ruiz et al., 2014) y 70 días a una altura de $80 \mathrm{~cm}$ en bosque húmedo premontano en Costa Rica (Soto et al., 2009). También se ha usado una altura de corte del botón de oro,a $50 \mathrm{~cm}$ y a intervalos de 56 días (Ríos y Salazar, 1995; Ekeocha, 2012; Gallego, 2016).

El botón de oro se puede sembrar a 3 y $4 \mathrm{~m}$ de distancia entre surcos para sistemas de pastoreo (Alonso et al., 2012; Ruiz et al., 2014), y entre plantas a 0,5 a 0,75 y $1 \mathrm{~m}$ (Solarte, et al., 2013), con el primer pastoreo a una altura de 1 a 1,5 m (Alonso et al., 2013). Para el sistema de corte y acarreo, las distancias de siembra pueden estar entre 0,5 m x 1,0 m (Mahecha et al., 2007), 0,75 m x 1,0 m (Ríos y Salazar, 1995) y 1,0 m x 1,0 m (Castillo-Mestre et al., 2016).

En cuanto a la propagación, establecimiento y manejo del matarratón, si es por semilla sexual, la germinación puede ocurrir a los siete días post-siembra (Cubillos-Hinojosa et al., 2011), el tiempo varía en función de la época del año, la calidad del suelo o sustrato, entre otras condiciones de establecimiento. En bancos forrajeros, el primer corte puede realizarse entre los cuatro a ocho meses de edad, entre 40 y $93 \mathrm{~cm}$ del suelo, y cuando la planta haya alcanzado 1,5 m de altura (López, 2005; Cuervo-Jiménez et al., 2013). La frecuencia de cortes de G. sepium puede variar entre los 56 a 90 días a una altura de $40 \mathrm{~cm}$ del suelo, según la capacidad de rebrote y tasa de crecimiento de la planta (Cardozo, 2013; Verdecia et al., 2014; Castañeda et al., 2016). En bancos forrajeros se ha establecido matarratón a distancias entre plantas de $1,0 \mathrm{~m}$ x 1,0 m, de $0,8 \mathrm{~m}$ x 0,5 m, 0,5 m x 0,5 m y 1,0 m x 0,25 m (López, 2005; Calle y Murgueitio, 2007; Cuervo-Jiménez et al., 2013).

En el caso de la cratylia, presenta germinación variable de acuerdo con la calidad de semilla, las condiciones de siembra y los factores medioambientales, en un rango de ocho a veinte días, y crecimiento lento en los primeros dos meses de establecimiento (Lascano et al., 2002; Arango et al., 2016). Se recomienda sembrarla a distancias entre 1,5 m x 1,0 m, 1,0 m x 1,0 m o 1,0 m x 0,5 m para bancos forrajeros (Lascano et al., 2002). En cuanto a la 
altura y frecuencia de corte puede realizarse a los cuatro meses, con altura entre los 30 y $90 \mathrm{~cm}$, y cortes suscesivos entre 1,5 y 4 meses (Lascano et al., 2002; Arango et al., 2016; Sotelo et al., 2017).

Con relación a la siembra de totumo, el porcentaje de germinación de la semilla se ha estimado entre el 86 y $91 \%$ a los 10 y 91 días, respectivamente (Rodríguez y Roncallo, 2013). El totumo se ha establecido como estrato arbustivo en arreglos silvopastoriles de ramoneo en el Caribe colombiano, con rotación de potreros cada veintiocho días de reposo y tiempo de ocupación de dos días (Barragán, 2013). Por su parte, Rodríguez y Roncallo (2013) concluyeron que de acuerdo con la época, podía manejarse 72 días de reposo en la época seca y 45 días en época lluviosa. En cuanto al manejo en banco forrajero, los cortes pueden realizarse entre los dos a cuatro meses de edad (Rodríguez y Roncallo, 2013). Una de las bondades del totumo, es el aprovechamiento del fruto, el cual puede ser usado para la elaboración de ensilaje (Calle et al., 2011a; Ejelonu et al., 2011).

\section{Producción de biomasa y perfil nutricional}

Factores intrínsecos como las características de la especie arbustiva y extrínsecos como el clima, el tipo de suelo, la densidad de siembra y la época del año, influyen tanto en la producción de forraje como en las características bromatológicas de la planta (Flórez, 2012; Ruiz et al., 2012; Arango et al., 2016; Gallego, 2016; Londoño et al., 2019). Se ha observado que la época (seca o lluviosa) influye en la producción de forraje del botón de oro, con una producción de materia seca por hectárea en época lluviosa y seca entre 5 a 5,5 y 3,5 a 4,5 t ha ${ }^{-1}$ MS a los 60 y 80 días de edad, respectivamente (Ruiz et al., 2012). En cuanto a producción de forraje verde y materia seca, en el botón de oro se reportan valores más altos, seguido de la cratylia, el matarratón y el totumo, sin embargo, suele hallarse mayores estudios en T. diversifolia, especialmente de climas medios a fríos y suelos con buena fertilidad, que de C. argentea, G. sepium, y C. cujete (Cuadros 2 y 3 ).

Cuadro 2. Valores promedio de producción de forraje verde de las especies T. diversifolia, G. sepium, C. argentea, y C. cujete, reportados por diversos autores en condiciones tropicales. Colombia. 2018.

Table 2. Averages values of fresh forage production of T. diversifolia, G. sepium, C. argentea, and C. cujete, reported by several authors in low tropic conditions. Colombia. 2018.

\begin{tabular}{|c|c|c|}
\hline Especie & Producción de forraje verde & Referencia \\
\hline T. diversifolia & $\begin{array}{l}31 \mathrm{t} \mathrm{ha}^{-1}(0,75 \mathrm{~m} \times 0,75 \mathrm{~m}) ; 21,2 \mathrm{t} \mathrm{ha}^{-1}(1 \mathrm{~m} \times 0,75 \mathrm{~m}) \times \text { corte. } \\
23,48 \text { (estaca), } 17,66 \text { (semilla sexual con manejo in vitro), } 21,81 \text { (semilla } \\
\text { sexual) x corte. } \\
\text { Prefloración: } 24,7 \mathrm{t} \mathrm{ha}^{-1}\end{array}$ & $\begin{array}{l}\text { Ríos y Salazar (1995) } \\
\text { Gallego (2016) } \\
\text { Ferreira et al. (2016) }\end{array}$ \\
\hline G. sepium & $\begin{array}{l}\text { corte a los } 2 \text { meses: } 17,5 \mathrm{t} \mathrm{ha}^{-1} \mathrm{año}^{-1} \text {; corte a los } 4 \text { meses: } 16,26 \\
\mathrm{t} \mathrm{ha}^{-1} \mathrm{año}^{-1} \text {; corte a los } 6 \text { meses: } 15,02 \mathrm{t} \mathrm{ha}^{-1} \mathrm{año}^{-1} \\
\text { época seca: } 25,1 \mathrm{t} \mathrm{ha}^{-1} \\
\text { época lluviosa: } 60 \mathrm{t} \mathrm{ha}^{-1} \mathrm{año}^{-1}\end{array}$ & $\begin{array}{l}\text { Vennila et al. (2016) } \\
\text { López (2005) } \\
\text { Sarria (1999) }\end{array}$ \\
\hline C. argentea & $\begin{array}{l}\text { 12346-111000: 4,5-31 t ha-1 por corte cada } 120 \text { días. } \\
90 \text { días: Baja fertilidad 10,2 (manual) t/ha; } 13,33 \text { (mecanizado) t ha-1. } \\
\text { c/d } 60 \text { d: } 31,3(1)-29,5(\mathrm{pl}) \text { c/d } 75 \text { d: } 50,7(1)-40,6(\mathrm{pl}) \\
\text { c/d } 90 \text { d: } 41,7(\mathrm{l})-36,3(\mathrm{pl})\end{array}$ & $\begin{array}{l}\text { Lascano et al. (2002) } \\
\text { Rincón (2005) } \\
\text { López y Briceño } \\
\text { (2016) }\end{array}$ \\
\hline C. cujete & $\begin{array}{l}\text { Forraje: } 14-16 \mathrm{t} \mathrm{ha}^{-1} \text {. Fruto: } 20 \mathrm{t} \mathrm{ha}^{-1} \text { época seca } \\
\text { Máximo desde } 8 \text { años } 27 \mathrm{~kg} \text { fruto por árbol/año }\end{array}$ & $\begin{array}{l}\text { Gómez et al. (2015) } \\
\text { Flórez (2012) }\end{array}$ \\
\hline
\end{tabular}

Es preciso resaltar, que con el aumento de la edad, varían las características nutricionales de estas especies (Lascano et al., 2002; Rodríguez y Roncallo, 2013; Gómez et al., 2015; Gallego, 2016; Ruiz et al., 2017; Sotelo 
Cuadro 3. Valores promedio de producción de materia seca de T. diversifolia, G. sepium, C. argentea, y C. cujete, reportados por diversos autores en condiciones tropicales. Colombia. 2018.

Table 3. Averages values of dry matter production of T. diversifolia, G. sepium, C. argentea, and C. cujete, reported by several authors in low tropic conditions. Colombia. 2018.

\begin{tabular}{|c|c|c|}
\hline Especie & Producción de forraje verde & Referencia \\
\hline T. diversifolia & $\begin{array}{l}\text { 3,52 } \mathrm{tha}^{-1} \mathrm{año}^{-1} \mathrm{MS} \\
\mathrm{t} \mathrm{ha}^{-1} \mathrm{año}^{-1} \mathrm{MS}: 19,5 \text { (estaca), } 14,9 \text { (semilla sexual con tratamiento in vitro), } \\
17,7 \text { (semilla sexual) } \\
\text { Época lluviosa: } 5-5,5 \mathrm{t} \mathrm{ha}^{-1} \mathrm{MS} 60 \text { días; } \\
\text { Época seca: } 3,5-4,5 \mathrm{t} \mathrm{ha}^{-1} \mathrm{MS} \text { a } 80 \text { días. } \\
\text { Prefloración: } 5,6 \mathrm{tha}^{-1}\end{array}$ & $\begin{array}{l}\text { Castillo-Mestre et al. (2016) } \\
\text { Gallego (2016) } \\
\text { Ruiz et al. (2012) } \\
\text { Ferreira et al. (2016) }\end{array}$ \\
\hline G. sepium & $\begin{array}{l}\text { Época seca: } 8,57 \mathrm{tha}^{-1} \mathrm{año}^{-1} \\
\text { Rendimiento cultivo en callejones: } 1,68 \mathrm{t} \mathrm{ha}^{-1}\end{array}$ & $\begin{array}{l}\text { López (2005) } \\
\text { Palma (2006) }\end{array}$ \\
\hline C. argentea & $\begin{array}{l}\text { 14-20 t ha-1 año } \\
2-5 \mathrm{t} \mathrm{ha}^{-1} \text { en ocho semanas } \\
2580 \mathrm{~kg}^{-1} \text { ha }{ }^{-1} \pm 212 \text { (follaje) } \\
\mathrm{t} \mathrm{ha}^{-1} \mathrm{año}^{-1} \mathrm{MS} \\
\mathrm{c} / \mathrm{d} 60 \mathrm{~d}: 6,3(1)-6,4(\mathrm{pl}) \mathrm{c} / \mathrm{d} 75 \mathrm{~d}: 10,9(\mathrm{l})-10,1(\mathrm{pl}) \mathrm{c} / \mathrm{d} 90 \mathrm{~d}: 10,8(1)-9,6(\mathrm{pl})\end{array}$ & $\begin{array}{l}\text { Lascano et al. (2002) } \\
\text { Arango et al. (2016) } \\
\text { Rincón (2005) } \\
\text { López y Briceño (2016) }\end{array}$ \\
\hline Crescentia cujete & $\begin{array}{l}\text { Follaje y tallos: } \mathrm{kg} \mathrm{ha}^{-1} \text { MS } 2 \text { meses }(235,7), 3 \text { meses }(281,7), 4 \text { meses } \\
(689,2) \\
\text { Fruto: } 11 \mathrm{t} \mathrm{ha}^{-1} \mathrm{año}^{-1} \mathrm{MS}\end{array}$ & $\begin{array}{l}\text { Rodríguez y Roncallo et al. } \\
\text { (2013) } \\
\text { Gómez et al. (2015) }\end{array}$ \\
\hline
\end{tabular}

et al., 2017; Londoño et al., 2019). Por ejemplo, en el caso de G. sepium el porcentaje de proteína a los tres y seis meses decreció con la edad, con valores de $28,31 \%$ y 26,46 \%, respectivamente (Araque et al., 2006); de manera similar ocurre con el botón de oro, donde a los a los cincuenta días se reportó un 18,52 \% (Nieves et al., 2011), mientras que a los sesenta días se reportaron porcentajes de proteína entre 19,03\% (época seca) y 21,93\% (época lluviosa) (Lezcano et al., 2012a) (Cuadro 4).

\section{Compuestos fitoquímicos}

El botón de oro, matarratón, cratylia y totumo, contienen metabolitos secundarios que varían en concentración y presentación, según la especie, edad, parte de la planta y condiciones medioambientales. Estos metabolitos pueden generar cambios metabólicos y fisiológicos en los rumiantes, según la adaptación del animal y los mecanismos de respuesta del organismo (Estell, 2010). Del botón de oro se han aislado unos 150 compuestos secundarios (Zhao et al., 2012), cuya proporción puede variar de acuerdo con las condiciones abióticas en las que se desarrolle la planta, como lluvia y la temperatura, la fenología, la edad de utilización de la planta, e incluso por el estrés hídrico (Cardona-Iglesias et al., 2016).

En la T. diversifolia se han identificado flavonoides, diterpenos, sesquiterpenos lactonas, fenoles, taninos, triterpenos-esteroides y alcaloides, en hojas y tallos (Fasuyi et al., 2010; Chagas et al., 2012; Lezcano et al., 2012b), y se cree que la presencia de metabolitos en flores y raíces se ve influenciada por las características edafológicas en cuanto a concentraciones de nutrientes como calcio, magnesio, fósforo, potasio y cobre (Ruiz et al., 2017). Entre los compuestos hallados en el botón de oro están la catequina y saponinas (triterpenoides), a las que se les atribuye una posible capacidad de reducción de la producción de metano en el rumen (Miranda et al., 2015; Gallego, 
Cuadro 4. Valores promedio de la composición nutricional de T. diversifolia, G. sepium, C. argentea, y C. cujete, reportada por varios autores para condiciones tropicales. Colombia. 2018.

Table 4. Average values of the nutritional composition of T. diversifolia, G. sepium, C. argentea, and C. cujete, reported by several authors for tropical conditions. Colombia. 2018.

\begin{tabular}{|c|c|c|c|}
\hline Especie & Variable & Valor & Referencia \\
\hline \multirow{5}{*}{ T. diversifolia } & FDN \% & $\begin{array}{l}40,4(\mathrm{es}) ; 43,6(\mathrm{el}) \\
32,94 \\
39\end{array}$ & $\begin{array}{l}\text { Verdecia et al. (2011) } \\
\text { Nieves et al. (2011) } \\
\text { Cardona-Iglesias et al. (2017) }\end{array}$ \\
\hline & FDA $\%$ & $\begin{array}{l}24,1(\mathrm{es}) ; 27,6(\mathrm{el}) \\
34,48(\mathrm{~h}+\mathrm{t}) \\
27,2\end{array}$ & $\begin{array}{l}\text { Verdecia et al. (2011) } \\
\text { Naranjo y Cuartas (2011) } \\
\text { Cardona-Iglesias et al. (2017) }\end{array}$ \\
\hline & $\mathrm{CNE} \%$ & $\begin{array}{l}9,65-18,41 \\
7,82(\mathrm{~s}) ; 8,5(\mathrm{es})\end{array}$ & $\begin{array}{l}\text { Medina et al. (2009) } \\
\text { Gallego-Castro et al. (2017) }\end{array}$ \\
\hline & $\% \mathrm{PC}$ & $\begin{array}{l}13,31 \text { (se); } 14,10 \text { (est) } \\
60 \text { días de edad: es } 27,4 \text { (es), } 28,7 \text { (el) } \\
17,2\end{array}$ & $\begin{array}{l}\text { Gallego-Castro et al. (2017) } \\
\text { Verdecia et al. (2011) } \\
\text { Cardona-Iglesias et al. (2017) }\end{array}$ \\
\hline & MS \% & $\begin{array}{l}18,2 \text { (es);19,7 (el) } \\
60 \text { días: } 12,78 \text { (es); } 10,13 \text { (el) } \\
12,45 \text { (se); } 12,74 \text { (est) }(56 \text { días) }\end{array}$ & $\begin{array}{l}\text { Verdecia et al. (2011) } \\
\text { Lezcano et al. (2012a) } \\
\text { Gallego-Castro et al. (2017) }\end{array}$ \\
\hline \multirow{5}{*}{ G. sepium } & FDN \% & $\begin{array}{l}37,23 \\
55,9 \\
34,72 \text { (49 días) } \\
\end{array}$ & $\begin{array}{l}\text { Puerto (2012) } \\
\text { León et al. (2012) } \\
\text { AGROSAVIA (2018) }\end{array}$ \\
\hline & FDA $\%$ & $\begin{array}{l}35,77 \\
21,08 \text { (49 días) }\end{array}$ & $\begin{array}{l}\text { Puerto (2012) } \\
\text { AGROSAVIA (2018) }\end{array}$ \\
\hline & $\mathrm{CNE} \%$ & 20,7 & Puerto (2012) \\
\hline & $\% \mathrm{PC}$ & $\begin{array}{l}3 \text { meses: } 28,31 ; 6 \text { meses: } 26,46 \\
28,31-20,64 \\
20-23\end{array}$ & $\begin{array}{l}\text { Araque et al. (2006) } \\
\text { Cuervo-Jiménez et al. ( 2013) } \\
\text { Sarria (1999) }\end{array}$ \\
\hline & MS \% & $\begin{array}{l}19,7 \text { ( } 49 \text { días) } \\
8,75 \text { a } 13,39 \\
3 \text { meses: } 8,75 ; 6 \text { meses: } 10,10 \\
\end{array}$ & $\begin{array}{l}\text { AGROSAVIA (2018) } \\
\text { Araque et al. (2006) } \\
\text { Cuervo-Jiménez et al. ( 2013) }\end{array}$ \\
\hline \multirow{5}{*}{ C. argentea } & FDN \% & $\begin{array}{l}64-70 \text { (90 días) } \\
64,5 \text { (60 días) } \\
43,2-50,8 \\
\end{array}$ & $\begin{array}{l}\text { Lascano et al. (2002) } \\
\text { Rincón (2005) } \\
\text { Roa et al. (2017) }\end{array}$ \\
\hline & FDA $\%$ & $\begin{array}{l}42,4 \text { (90 días) } \\
34,2-40,6\end{array}$ & $\begin{array}{l}\text { Lascano et al. (2002) } \\
\text { Roa et al. (2017) }\end{array}$ \\
\hline & $\mathrm{CNE} \%$ & $\begin{array}{l}60 \text { d: } 13,29 \text { (es), 11,78 (el) } \\
9,81\end{array}$ & $\begin{array}{l}\text { López y Briceño (2016) } \\
\text { AGROSAVIA (2018) }\end{array}$ \\
\hline & $\% \mathrm{PC}$ & $\begin{array}{l}13-23(\mathrm{~h}+\mathrm{t})(90 \text { días }) \\
16,3-20,1\end{array}$ & $\begin{array}{l}\text { Lascano et al. (2002) } \\
\text { Roa et al. (2017) }\end{array}$ \\
\hline & MS \% & $\begin{array}{l}28,8-33,2 \\
60 \text { días: } 24,43(\mathrm{es}), 19,5(\mathrm{el})\end{array}$ & $\begin{array}{l}\text { Roa et al. (2017) } \\
\text { López y Briceño (2016) }\end{array}$ \\
\hline \multirow{5}{*}{ C. cujete } & FDN $\%$ & $\begin{array}{l}\text { hojas y tallos verdes: } \\
\text { es: } 2 \text { meses }(48,8), 3 \text { meses }(48,8) ; 4 \text { meses } \\
(52,8) \\
52,65\end{array}$ & $\begin{array}{l}\text { Rodríguez y Roncallo (2013) } \\
\text { AGROSAVIA (2018) }\end{array}$ \\
\hline & FDA $\%$ & $\begin{array}{l}\text { hojas y tallos verdes: } \\
20,67 \\
48,36-52,53\end{array}$ & $\begin{array}{l}\text { AGROSAVIA (2018) } \\
\text { Barragán (2013) }\end{array}$ \\
\hline & $\mathrm{CNE} \%$ & Follajes y tallos verdes: 5,16 & AGROSAVIA (2018) \\
\hline & $\% \mathrm{PC}$ & $\begin{array}{l}\text { follaje y tallos verdes: } \\
14,58-15,66 \\
\text { es: } 2 \text { meses }(15,8), 3 \text { meses }(14,9) ; 4 \text { meses }(14) \\
13,4\end{array}$ & $\begin{array}{l}\text { Barragán (2013) } \\
\text { Rodríguez y Roncallo (2013) } \\
\text { AGROSAVIA (2018) }\end{array}$ \\
\hline & MS \% & $\begin{array}{l}\text { follaje y tallos verdes: } 31,83 \\
\text { es: } 2 \text { meses } \\
(15,8) ; 3 \text { meses }(14,9) ; 4 \text { meses }(14)\end{array}$ & $\begin{array}{l}\text { AGROSAVIA (2018) } \\
\text { Rodríguez y Roncallo (2013) }\end{array}$ \\
\hline
\end{tabular}

FDN\%: fibra en detergente neutro / fiber in neutral detergent. FDA\%: fibra en detergente ácida / fiber in acid detergent. CNE: carbohidratos no estructurales / non structural carbohydrates. \% PC: proteína cruda / crude protein. MS \%: materia seca / dry matter. se: semilla / seed. est: estaca / stake. es: época seca / dry season. el: epoca lluviosa / rainy season. h+t: hojas más tallos / leaves and stems. 
2016; Cardona-Iglesias et al., 2017), ya que pueden aumentar las bacterias celulolíticas, disminuir la población metanogénica y favorecer la disponibilidad de nutrientes (Ruiz et al., 2014; Gutiérrez et al., 2017).

El matarratón contiene terpenoides, compuestos fenólicos como cumarinas y taninos, saponinas y glucósidos que podrían estar relacionados con sus propiedades fitoquímicas (Sajani y Sujatha, 2017). En rumiantes, el consumo de compuestos fenólicos presentes en las hojas, favorece la proteína sobrepasante (Cuervo-Jiménez et al., 2013). El G. sepium puede tener un efecto antiparasitario en terneros, al inhibir la etapa larvaria de Cooperia punctata (Von-Son-de Fernex et al., 2018). Se ha investigado también, su efecto aleloquímico sobre otras especies de plantas (Takemura et al., 2013). G. sepium tiene propiedades antimicrobiales contra bacterias gram positivas y gram negativas (Nazli et al., 2011). La cratylia ha sido poco estudiada en términos de compuestos fitoquímicos, aunque se reporta la presencia de fenoles y taninos, en muy bajas proporciones (AGROSAVIA, 2018), siendo considerada como una especie baja en taninos (Stürm et al., 2007). En lo que respecta al totumo, ha sido estudiado por sus propiedades antioxidantes, antiinflamatorias y antibacteriales, lo que se le atribuye a la presencia de compuestos fenólicos (Lizcano et al., 2010; Das et al., 2014; Parvin et al., 2015).

\section{Ensilaje de arbustivas}

Ensilar permite a las ganaderías conservar alimento para épocas críticas como la sequía, y mejorar la oferta de macro y micro nutrientes en la dieta. Además de poder emplear recursos forrajeros locales y reducir los costos de producción, ensilar, podría contribuir a mejorar los parámetros productivos y adquirir resiliencia frente a los desafíos devenidos con el cambio climático (Arango et al., 2016; García et al., 2017; Sotelo et al., 2017). La elaboración de ensilajes suele ir acompañada de aditivos para promover la acidificación, como el ácido láctico (Oliveira et al., 2017), contrarrestar la presencia de microorganismos indeseables como el ácido propiónico, ácido benzoico (Dunière et al., 2013), favorecer las características nutricionales del producto final bien sea con urea o amoniaco (Santos-da-Silva et al., 2014), o para mejorar el proceso de fermentación tales como, bacterias acidolácticas, fuentes de carbohidratos como la melaza y enzimas (Ni et al., 2017). Uno de los aditivos más usados es la melaza, ya que contribuye al incremento del nivel de ácido láctico en la fase fermentativa al ofrecer mayor sustrato (carbohidratos) a las bacterias ácido lácticas, lo cual es importante en aquellos ensilajes elaborados a partir de especies con bajo contenido de carbohidratos solubles (Li et al., 2014; Desta et al., 2016). La adición de cabohidratos contibuye a preservar las características nutricionales del forraje ensilado (Li et al., 2014). La adición de melaza junto con bacterias ácido lácticas, podría mejorar el recuento de Lactobacillus deseables e inhibir microorganismos indeseables tales como Clostridia y Enterobacter (Ni et al., 2017).

El botón de oro (Fasuyi et al., 2010; Fasuyi y Okeke, 2014), la cratylia (Roa y Galeano, 2015) y el matarratón (Carvalho et al., 2017), han sido utilizadas en elaboración de ensilajes, de manera individual, así como asociadas a otras especies de interés forrajero, es el caso del matarratón, que ha sido usado en ensilajes mixtos con caña (Saccharum officinarum) (Suárez et al., 2011) e incluso con yuca (Manihot esculenta Crantz) (Oliveira et al., 2018). En cuanto al totumo, el fruto puede ser utilizado para hacer ensilaje de tipo salino; la pulpa de $C$. cujete aporta carbohidratos altamente fermentables, siendo recomendado el uso del fruto maduro, ya que la presencia de glucósidos es menor (Flórez, 2012).

En cuanto a la elaboración de un ensilaje mixto a base de estas cuatro especies, en lo revisado no se hallaron reportes al respecto, sin embargo, sí se informa de diversos valores nutricionales para ensilajes de cada especie (Cuadro 5). Se hallan principalmente resultados de T. diversifolia, seguidos de G. sepium y, en poca proporción, de $C$. argentea y C. cujete. Resalta en estos ensilajes, que el porcentaje de proteína cruda suele ser alto, siendo significativamente superiores los valores para cratylia con un valor estimado de 19,12\% (Bernal et al., 2008), seguido del matarratón con valores entre 15,7 (AGROSAVIA, 2018) a 18,17 \% (Campos et al., 2017), con relación 
Cuadro 5. Valores promedio del perfil nutricional y calidad de ensilaje de las especies T. diversifolia, G. sepium, C. argentea, y C. cujete, reportados por diversos autores. Colombia. 2018.

Table 5. Average values of the nutritional profile and quality of silage of the T. diversifolia, G. sepium, C. argentea, and C. cujete, reported by several authors. Colombia. 2018.

\begin{tabular}{|c|c|c|c|}
\hline Especie & Variable & Valor & Referencia \\
\hline \multirow{8}{*}{ Tithonia diversifolia } & $\% \mathrm{PC}$ & 10,02 & AGROSAVIA (2018) \\
\hline & $\% \mathrm{MS}$ & $\begin{array}{c}27,2 \\
20\end{array}$ & $\begin{array}{l}\text { Roa y Galeano (2015) } \\
\text { AGROSAVIA (2018) }\end{array}$ \\
\hline & FDN \% & $\begin{array}{c}50,7 \\
51,75\end{array}$ & $\begin{array}{l}\text { Roa y Galeano (2015) } \\
\text { AGROSAVIA (2018) }\end{array}$ \\
\hline & FDA $\%$ & 20,59 & AGROSAVIA, (2018) \\
\hline & NT \% & 2,32 & Roa y Galeano (2015) \\
\hline & Ácido láctico \% & 3,22 & Roa y Galeano (2015) \\
\hline & $\mathrm{pH}$ & 4,54 & Roa y Galeano (2015) \\
\hline & $\mathrm{N}-\mathrm{NH} 3 / \mathrm{N}$ total $\%$ & 0,79 & Roa y Galeano (2015) \\
\hline \multirow{7}{*}{ Gliricidia sepium } & $\% \mathrm{PC}$ & $\begin{array}{c}18,17 \\
15,7\end{array}$ & $\begin{array}{l}\text { AGROSAVIA (2018) } \\
\text { Campos et al. (2017) }\end{array}$ \\
\hline & $\% \mathrm{MS}$ & $\begin{array}{c}33,92 \\
26,3\end{array}$ & $\begin{array}{l}\text { AGROSAVIA (2018) } \\
\text { Campos et al. (2017) }\end{array}$ \\
\hline & FDN \% & $\begin{array}{c}39,81 \\
54,6\end{array}$ & $\begin{array}{l}\text { AGROSAVIA (2018) } \\
\text { Campos et al. (2017) }\end{array}$ \\
\hline & FDA $\%$ & $\begin{array}{l}17,1 \\
40,0\end{array}$ & $\begin{array}{l}\text { AGROSAVIA (2018) } \\
\text { Campos et al. (2017) }\end{array}$ \\
\hline & Ácido láctico \% & 4,84 & Carvalho et al. (2017) \\
\hline & $\mathrm{pH}$ & 4,2 & Carvalho et al. (2017) \\
\hline & $\mathrm{N}-\mathrm{NH} 3 / \mathrm{N}$ total $\%$ & 6,5 & Carvalho et al. (2017) \\
\hline \multirow{8}{*}{ Cratylia argentea } & $\% \mathrm{PC}$ & 19,12 & Bernal et al. (2008) \\
\hline & $\% \mathrm{MS}$ & 34,8 & Roa y Galeano (2015) \\
\hline & FDN \% & $\begin{array}{c}49,5 \\
59,14\end{array}$ & $\begin{array}{l}\text { Roa y Galeano (2015) } \\
\text { Bernal et al. (2008) }\end{array}$ \\
\hline & FDA $\%$ & 41,35 & Bernal et al. (2008) \\
\hline & NT \% & 1,58 & Roa y Galeano (2015) \\
\hline & Ácido láctico \% & 3,55 & Roa y Galeano (2015) \\
\hline & $\mathrm{pH}$ & 4,29 & Roa y Galeano (2015) \\
\hline & $\mathrm{N}-\mathrm{NH} 3 / \mathrm{N}$ total $\%$ & 1 & Roa y Galeano (2015) \\
\hline \multirow{4}{*}{$\begin{array}{l}\text { Crescentia cujete: } \\
\text { ensilaje del fruto }\end{array}$} & $\% \mathrm{PC}$ & $\begin{array}{c}9,70 \\
8,84-10,56\end{array}$ & $\begin{array}{l}\text { Gómez et al. (2015) } \\
\text { Flórez (2012) }\end{array}$ \\
\hline & $\% \mathrm{MS}$ & 22,6 & Gómez et al. (2015) \\
\hline & FDN \% & 22,54 & Gómez et al. (2015) \\
\hline & FDA $\%$ & 21,28 & Gómez et al. (2015) \\
\hline
\end{tabular}

PC: proteína cruda / crude protein. MS: materia seca/dry matter. FDN: fibra en detergente neutro/ fiber in /neutral detergent. FDA: fibra en detergente ácido / fiber in acid detergent. CNE: carbohidratos no estructurales / non structural carbohydrates. LAD: lignina detergente ácida/acid detergent lignin. D.E: digestibilidad efectiva/effective digestibility. DIVMS: digestibilidad in vitro de materia seca / in vitro dry matter digestibility. NT: nitrógeno total/total nitrogen. $\mathrm{N}-\mathrm{NH} 3 / \mathrm{N}$ total \%: \% nitrógeno amoniacal de nitrógeno total / ammonia nitrogen of total nitrogen \%.

a los del botón de oro que puede estar en un 10,02\% (AGROSAVIA, 2018) y el totumo en un rango de 8,84 a 10,56 $\%$ (Flórez, 2012). Cabe resaltar además, que la composición nutricional de un ensilaje, va a variar con factores como 
la edad y época de corte de las plantas (Dunière et al., 2013), y que la calidad del ensilaje puede estar vinculada con el manejo dado en el proceso de elaboración del mismo, el uso de aditivos y el método de almacenamiento de este (Borreani et al., 2018). Es preciso señalar, que para algunas de las variables de calidad de ensilaje como en $C$. cujete y G. sepium, dentro de los estudios analizados en esta revisión, no se hallaron reportes para algunas variables de calidad del ensilaje.

\section{Conclusiones}

El botón de oro, matarratón, cratylia y totumo, son especies que se adaptan a condiciones diversas de altitud, temperatura ambiental y adversas como la baja fertilidad de los suelos y pobre precipitación anual, y podrían representar una alternativa con beneficios multidimensionales para las ganaderías. A partir de lo revisado en las especies T. diversifolia, G. sepium, C. argentea y C. cujete, se considera pertinente realizar estudios encaminados a evaluar la respuesta productiva de estas especies de interés forrajero en ganaderías de trópico bajo, toda vez que, en los reportes y estudios analizados, se observó con mayor frecuencia evaluaciones agronómicas. Estas especies podrían ser evaluadas para arreglos silvopastoriles en potreros y en bancos forrajeros, para ofertar en fresco o elaborando ensilajes solos o mixtos. De igual forma, abordar estas especies como alternativas de suplementación estratégica en bovinos con recursos forrajeros locales, sería relevante en las ganaderías del trópico bajo, considerando los desafíos que supone el cambio climático, las duras épocas secas y la necesidad de una ganadería sostenible en términos ambientales, y sustentable en términos económicos.

\section{Agradecimientos}

Los autores agradecen al departamento de formación académica de Haciendas y a la estrategia sostenibilidad 2018-2019 de la Universidad de Antioquia, por el apoyo logístico y financiero para el desarrollo del proyecto "Uso de arbustivas forrajeras en la cría y levante de ganado BON x Cebú en Caucasia, Antioquia".

\section{Literatura citada}

AGROSAVIA (Corporación Colombiana de Investigación Agropecuaria). 2018. Alimentro: composición química y valor nutricional. AGROSAVIA, COL. http://www.corpoica.org.co:8086/NetCorpoicaMVC/AlimenTro/Estadisticas/ ReporteAnalisis (consultado 22 mar. 2018).

Alonso, J., G. Achang, L. Santos, y R. Sampaio. 2013. Productividad de Tithonia diversifolia y conducta animal a diferentes momentos de comenzar el pastoreo. Livest. Res. Rural Dev. 25(11). http://www.lrrd.org//rrd25/11/alon25192.html (consultado 29 mar. 2018).

Alonso, J., T. Ruiz, G. Achang, L. Santos, y R. Sampaio. 2012. Producción de biomasa y comportamiento animal en pastoreo con Tithonia diversifolia a diferentes distancias de plantación. Livest. Res. Rural Dev. 24(9). http://www.lrrd.org/lrrd24/9/ lazo24160.htm (consultado 15 mar. 2018).

Arango, J., A. Bohorquez, M. Duque, and B. Maas. 2009. Diversity of the calabash tree (Crescentia cujete L.) in Colombia. Agroforest. Syst. 76:543-553. doi:10.1007/s10457-009-9207-0

Arango, J., J. Gutiérrez, J. Mazabel, P. Pardo, K. Enciso, S. Burkart, M. Sotelo, B. Hincapié, I. Molina, Y. Herrera, y G. Serrano. 2016. Estrategias tecnológicas para mejorar la productividad y competitividad de la actividad ganadera: Herramientas para enfrentar el cambio climático. Publicación no. 414. CIAT, Cali, COL. 
Araque, C., T. Quijada, R. Aubeterre, L. Páez, A. Sánchez, y F. Espinoza. 2006. Bromatología del mataratón (Gliricidia sepium) a diferentes edades de corte en Urachiche, estado Yaracuy, Venezuela. Zootec. Trop. 24:393-399.

Bacab, H., N. Madera, F. Solorio, F. Vera, y D. Marrufo. 2013. Los sistemas silvopastoriles intensivos con Leucaena leucocephala: Una opción para la ganadería tropical. Avanc. Invest. Agropecu.17(3):67-81.

Barahona, R., M. Sánchez, E. Murgueitio, y J. Chará,. 2014. Contribución de la Leucaena leucocephala lam (de wit) a la oferta y digestibilidad de nutrientes y las emisiones de metano entérico en bovinos pastoreando en sistemas silvopastoriles intensivos. Carta FEDEGÁN 140:66-69.

Barragán, W. 2013. Sistemas silvopastoriles para mejorar la producción de leche y disminuir el estrés calórico en la región Caribe colombiana. Tesis MSc., Universidad de Antioquia, COL.

Bernal, L., P. Ávila, G. Ramírez, C. Lascano, T. Tiemann, y H. Hess. 2008. Efecto del ensilaje y el heno de Calliandra calothyrsus, Flemingia macrophylla, Cratylia argentea y Vigna unguiculata sobre la producción de gas in vitro. Asoc. Latinoam. Prod. Anim. 16(3):97-103.

Borreani, G., E. Tabacco, R. Schmidt, B. Holmes, and R. Muck. 2018. Silage review: Factors affecting dry matter and quality losses in silages. J. Dairy Sci. 101:3952-3979. doi:10.3168/jds.2017-13837

Botero, S, y S. Martínez. 2016. Análisis productivo de dos modelos de suplementación a pastoreo para mitigar el impacto de la época seca en ganado de engorde en Montería, Colombia. Escuela Agrícola Panamericana, Zamorano, HND. https:// bdigital.zamorano.edu/bitstream/11036/6005/1/CPA-2017-024.pdf (consultado 13 mar. 2018).

Calle, Z., y E. Murgueitio. 2007. El matarratón: elemento esencial de los paisajes ganaderos tropicales. Carta FEDEGÁN 103:94-100.

Calle, Z., y E. Murgueitio. 2008. El botón de oro: arbusto de gran utilidad para sistemas ganaderos de tierra caliente y montaña. Carta FEDEGÁN 108:54-63.

Calle, Z., E. Murguieitio, y M. Botero. 2011a. Totumo: el árbol de las américas para la ganadería moderna. Carta FEDEGÁN 122:64-73.

Calle, Z., E. Murgueitio, y J. Caicedo. 2011b. Cómo enfrentar la sequía y la degradación extrema de tierras. Carta FEDEGÁN 151:62-69.

Campos, F.S., G. Carvalho, E. Santos, G. Araújo, G. Gois, R. Rebouças, A. Leão, S. Santos, J. Oliveira, L. Leite, M. Araujo, L. Cirne, R. Silva, and E. Carvalho. 2017. Influence of diets with silage from forage plants adapted to the semi-arid conditions on lamb quality and sensory attributes. Meat Sci. 124:61-68. doi:10.1016/j.meatsci.2016.10.011

Cardona-Iglesias, J., L. Mahecha-Ledesma, y J. Angulo-Arizala. 2016. Arbustivas forrajeras y ácidos grasos: estrategias para disminuir la producción de metano entérico en bovinos. Agron. Mesoam. 28:273-288. doi:10.15517/am.v28i1.21466

Cardona-Iglesias, J., L. Mahecha-Ledesma, y J. Angulo-Arizala. 2017. Efecto sobre la fermentación in vitro de mezclas de Tithonia diversifiolia, Cenchrus clandestinum y grasas poliinsaturadas. Agron. Mesoam. 28:405-426. doi:10.15517/ma.v28i2.25697

Cardozo, J. 2013. El matarratón (Gliricidia sepium) en la alimentación animal de rumiantes. Tesis Esp., Universidad Nacional Abierta y a Distancia, Bogotá, COL.

Carvalho, G., R. Rebouças, F. Campos, E. Santos, G. Araújo, G. Gois, J. Oliveira, R. Oliveira, L. Rufino, J. Azevedo, and L. Cirne. 2017. Intake, digestibility, performance, and feeding behavior of lambs fed diets containing silages of different tropical forage species. Anim. Feed Sci. Technol. 228:140-148. doi:10.1016/j.anifeedsci.2017.04.006

Castañeda, N.P., F. Álvarez, J. Arango, L. Chanchy, G.F. García, V. Sánchez, A. Solarte, M. Sotelo, y C. Zapata. 2016. Especies vegetales útiles para sistemas silvopastoriles del Caquetá. CIAT, Cali, COL. 
Castillo-Mestre, R., T. Betancourt-Bagué, O. Toral-Pérez, y J. Iglesias-Gómez. 2016. Influencia de diferentes marcos de plantación en el establecimiento y la producción de Tithonia diversifolia. Pastos y Forrajes 39(2):89-93.

Chagas, D., R. Oliveira, B. Rocha, and F. Da-Costa. 2012. Ethnobotany, chemistry, and biological activities of the genus Tithonia (Asteraceae). Chem. Biodivers. 9:210-235. doi:10.1002/cbdv.201100019

Chaverri, C., and J. Cicció. 2015. Leaf and flower essential oil compositions of Gliricidia sepium (Fabaceae) from Costa Rica. Am. J. Essent. Oil Nat. Prod. 2(3):18-23.

Cubillos-Hinojosa, J., P. Milian-Mindiola, and J. Hernández-Mulford. 2011. Biological nitrogen fixation by Rhizobium sp. native gliricidia (Gliricidia sepium [Jacq.] Kunth ex Walp.) under greenhouse conditions. Agron. Colomb. 29:465-472.

Cuervo-Jiménez, A., W. Narváez-Solarte, y C. Han-von-Hessberg. 2013. Características forrajeras de la especie Gliricidia sepium (Jacq) Stend, Fabaceae. Bol. Cient. Mus. Hist. Nat. 17(1):33-45.

Dahunsi, O., S. Oranusi, and E. Efeovbokhan. 2017. Anaerobic mono-digestion of Tithonia diversifolia (Wild Mexican sunflower). Energy Convers. Manag. 148:128-145. doi:10.1016/j.enconman.2017.05.056

Das, N., E. Islam, N. Jahan, M. Islam, A. Khan, R. Islam, and S. Parvin. 2014. Antioxidant activities of ethanol extracts and fractions of Crescentia cujete leaves and stem bark and the involvement of phenolic compounds. BMC Complem. Altern. Med. 14(45):1-9. doi:10.1186/1472-6882-14-45

Desta, S., X. Yuan, J. Li, and T. Shao. 2016. Ensiling characteristics, structural and nonstructural carbohydrate composition and enzymatic digestibility of Napier grass ensiled with additives. Bioresour. Technol. 221:447-454. doi:10.1016/j. biortech.2016.09.068

Dunière, L., J. Sindou, F. Chaucheyras-Durand, I. Chevallier, and D. Thévenot-Sergentet. 2013. Silage processing and strategies to prevent persistence of undesirable microorganisms. Anim. Feed Sci. Technol. 182:1-15. doi:10.1016/j. anifeedsci.2013.04.006

Ejelonu, B., A. Lasisi, A. Olaremu, and O. Ejelonu. 2011. The chemical constituents of calabash (Crescentia cujete). Afric. J. Biotech. 10:19631-19636. doi:10.1016/j.biortech.2016.09.068

Ekeocha, A. 2012. Performance of growing west african dwarf ewe fed mexican sunflower leaf meal based diets. J. Rec. Adv. Agric. 1(3):69-76.

Estell, R. 2010. Coping with shrub secondary metabolites by ruminants. Small Ruminant Res. 94:1-9. doi:10.1016/j. smallrumres.2010.09.012

Fasuyi, A., F. Dairo, and F. Ibitayo. 2010. Ensiling wild sunflower (Tithonia diversifolia) leaves with sugar cane molasses. Livest. Res. Rural Dev. 22(3). http://www.lrrd.org/lrrd22/3/fasu22042.htm (accessed Mar. 29, 2018).

Fasuyi, A., and P. Okeke 2014. Extrapolating nutritional potentials of ensiled wild sunflower (Tithonia diversifolia) leaf meal: proximate composition and functional properties. Int. J. Biol. Chem. Sci. 8:8-16. doi:10.4314/ijbcs.v8i1.2

FEDEGAN (Federación Colombiana de Ganaderos). 2006. Plan estratégico de la ganadería colombiana 2019. Sanmartín Obregón \& Cía, Bogotá, COL.

Ferreira, LH., R.S. Ribeiro, S.R. Silveira, G. Delarota, D.S. Freitas, J.P. Sacramento, D.S. Campos, e R.M. Maurício. 2016. Potencial forrageiro da Tithonia diversifolia para alimentação de ruminantes. Livest. Res. Rural Dev. 28(2). http://www. lrrd.org/lrrd28/2/ferr28017.html (consultado 28 feb. 2018).

Flórez, E. 2012. Evaluación de pulpa de totumo (Crescentia cujete L.) ensilada en dos estados de maduración como alternativa en alimentación bovina. Temas Agrarios 17(1):44-51. 
Fonte, L., M. Díaz, R. Machado, J. Demedio, A. García, D. Blanco. 2013. Caracterización físico-química y organoléptica de miel de Melipona beecheii obtenida en sistemas agroforestales. Pastos y Forrajes 36:345-349.

Fungo, B., J. Lehmann, K. Kalbitz, M. Tenywa, M. Thiongo, and H. Neufeldt. 2017. Emissions intensity and carbon stocks of a tropical Ultisol after amendment with Tithonia green manure, urea and biochar. Field Crops Res. 209:179-188. doi:10.1016/j.fcr.2017.05.013

Gallego, L. 2016. Evaluación agronómica y análisis productivo del botón de oro como suplemento alimenticio de vacas lecheras en trópico alto. Tesis MSc., Universidad de Antioquia, Antioquia, COL.

Gallego-Castro, L., L. Mahecha-Ledesma, y J. Angulo-Arizala. 2014. Potencial forrajero de Tithonia diversifolia Hemsl. A Gray en la producción de vacas lecheras. Agron. Mesoam. 25:393-403. doi:10.15517/am.v25i2.15454

Gallego-Castro, L., L. Mahecha-Ledesma, y J. Angulo-Arizala. 2017. Calidad nutricional de Tithonia diversifolia Hems1. A gray bajo tres sistemas de siembra en el trópico alto. Agron. Mesoam. 28:213-222. doi:10.15517/am.v28i1.21671

García, R., D. Gutiérrez, B. Chongo, and O. Gutiérrez. 2017. Feeding of cattle, sheep and goats with Tithonia diversifolia in Latin America and the Caribbean. In: L.L Savon et al., editors, Mulberry, moringa and tithonia in animal feed, and other uses. Chapter XIII. FAO, Rome, ITA. p. 237-250.

Gaviria-Uribe, X., J. Naranjo-Ramírez, D. Bolívar-Vergara, y R. Barahona-Rosales. 2015. Consumo y digestibilidad en novillos cebuinos en un sistema silvopastoril intensivo. Arch. Zootec. 64(245):21-27. doi:10.21071/az.v64i245.3

Gei, M., and J. Powers. 2015. The influence of seasonality and species effects on surface fine roots and nodulation in tropical legume tree plantations. Plant Soil 388:187-196. doi:10.1007/s11104-014-2324-1

Gómez, M., M. Botero, H. Anzola, and V. Giraldo. 2015. Totumo, sobreviviente a inundaciones y sequías. Carta FEDEGÁN 150:38-41.

Gutiérrez, O., O. La, I. Scull, and T. Ruiz. 2017. Nutritive value of Tithonia diversifolia for animal feeding. In: L.L Savon et al., editors, Mulberry, moringa and tithonia in animal feed, and other uses. Chapter XI. FAO, Rome, ITA. p. $203-221$.

Holguín, S., A. Ortiz, A. Velasco, y J. Mora. 2015. Evaluación multicriterio de 44 introducciones de Tithonia diversifolia (hemsl.) A. Gray en Candelaria, Valle del Cauca. Rev. Med. Vet. Zootec. 62(2):57-72. doi:10.15446/rfmvz.v62n2.5199

Hosseini, S., S.J. Trueman, T. Nevenimo, G. Hannet, P. Bapiwai, M. Poienou, and H.M. Wallace. 2017. Effects of shade-tree species and spacing on soil and leaf nutrient concentrations in cocoa plantations at 8 years after establishment. Agric. Ecosyst. Environ. 246:134-143. doi:10.1016/j.agee.2017.06.003

Lascano, C., A. Rincón, C. Plazas, P. Ávila, G. Bueno, y P. Argel. 2002. Veranera (Cratylia argentea (Desvaux) O. Kuntze): Leguminosa arbustiva de usos múltiples para zonas con periodos prolongados de sequía en Colombia. CORPOICA, y CIAT, Cali, COL. doi:10.13140/2.1.3483.5202

León, M., S. Martínez, R. Pedraza, y C. González. 2012. Indicadores de la composición química y digestibilidad in vitro de 14 forrajes tropicales. Rev. Prod. Anim. 24(1):1-6.

Lezcano, Y., M. Soca, F. Ojeda, E. Roque, D. Fontes, I. Montejo, H. Santana, J. Martínez, y N. Cubillas. 2012a. Caracterización bromatológica de Tithonia diversifolia (Hemsl.) A. Gray en dos etapas de su ciclo fisiológico. Pastos y Forrajes 35(3):275282.

Lezcano, Y., M. Soca, M., LM. Sánchez, F. Ojeda, Y. Olivera, D. Fontes, I. Montejo, y H. Santana. 2012b. Caracterización cualitativa del contenido de metabolitos secundarios en la fracción comestible de Tithonia diversifolia (Hemsl.) A. Gray. Pastos y Forrajes 35(3):283-292.

Li, M., X. Zi, H. Zhou, G. Hou, and Y. Cai,. 2014. Effects of sucrose, glucose, molasses and cellulase on fermentation quality and in vitro gas production of king grass silage. Anim. Feed Sci. Technol. 197:206-212. doi:10.1016/j.anifeedsci.2014.06.016 
Lizcano, L., F. Bakkali, M. Ruiz-Larrea, and J. Ruiz-Sanz. 2010. Antioxidant activity and polyphenol content of aqueous extracts from Colombian Amazonian plants with medicinal use. Food Chem. 119:1566-1570. doi:10.1016/j.foodchem.2009.09.043

Londoño, J., L. Mahecha, y J. Angulo. 2019. Desempeño agronómico y valor nutritivo de Tithonia diversifolia (Hemsl.) A Gray para la alimentación de bovinos. RECIA. 11(1). doi:10.24188/recia.v0.n0.2019.693

López, J. 2005. Procesos de fomento tecnológico de bancos de proteína de Gliricidia sepium. Resultados bioeconómicos y lecciones aprendidas para su difusión. Tesis M.Sc., CATIE, Turrialba, CRI.

López, M., y E. Briceño. 2016. Efecto de la frecuencia de corte y la precipitación en el rendimiento de Cratylia argentea orgánica. Nutr. Anim. Trop. 10(1):24-44. doi:10.15517/nat.v10i1.24703

Mahecha, L. 2002. El silvopastoreo: una alternativa de producción que disminuye el impacto ambiental de la ganadería bovina. Rev. Colomb. Cienc. Pecu. 15:226-231.

Mahecha, L., J. Escobar, J. Suárez, y L. Restrepo. 2007. Tithonia diversifolia (Hemsl.) Gray (botón de oro) como suplemento forrajero de vacas F1 (Holstein por Cebú). Livest. Res. Rural Dev. 17(2). http://www.lrrd.org/lrrd19/2/mahe19016.htm (consultado 29 mar. 2018).

Medina, M., E. García, L. González, L. Cova, y P. Morantinos. 2009. Variables morfo-estructurales y de calidad de la biomasa de Tithonia diversifolia en la etapa inicial de crecimiento. Zootec. Trop. 27(2):121-134.

Mejía-Díaz, E., L. Mahecha-Ledesma, y J. Angulo-Arizala. 2017. Tithonia diversifolia: especie para ramoneo en sistemas silvopastoriles y métodos para estimar su consumo. Agron. Mesoam. 28:289-302. doi:10.15517/am.v28i1.22673

Miranda, M., F. Macías, R. Varela, J. Ascension, S. Molinillo, and C. Gualtieri. 2015. Phytotoxins from Tithonia diversifolia. J. Nat. Prod. 78:1083-1092. doi:10.1021/acs.jnatprod.5b00040.

Moriones, L., y C. Montes. 2017. Aporte de Tithonia diversifolia en abonos orgánicos: Efecto en producción y suelo en Cauca, Colombia. Biotecnol. Sector Agropecu. Agroind. 15:101-111. doi:10.18684/BSAA(15)101-111

Murgueitio, E., R. Barahona, M. Flores, J. Chará, y J. Rivera. 2016. Es posible enfrentar el cambio climático y producir más leche y carne con sistemas silvopastoriles intensivos. Ceiba. 54(1):23-30. doi:10.5377/ceiba.v54i1.2774

Murgueitio, E., Z. Calle, F. Uribe, A. Calle, and B. Solorio. 2011. Native trees and shrubs for the productive rehabilitation of tropical cattle ranching lands. Forest Ecol. Manag. 261:1654-1663. doi:10.1016/j.foreco.2010.09.027

Naranjo, J., and C. Cuartas. 2011. Nutritional characterization and ruminal degradation kinetics of some forages with potential for ruminants supplementation in the highland tropics of Colombia. Rev. CES Med. Vet. Zootec. 6(1):9-19.

Navas, A. 2017. Conocimiento local y diseño participativo de sistemas silvopastoriles como estrategia de conectividad en paisajes ganaderos. Rev. Med. Vet. 34:55-65. doi:10.19052/mv.4255

Nazli, R., T. Sohail, B. Nawab, and Z. Yaqeen. 2011. Antimicrobial property of Gliricidia sepium plant extract. Pakistan J. Agric. Res. 24(1-4):1-4.

Ni, J., F. Wang, B.Y. Zhu, G. Zhou, Y. Pan, Y. Tao, and J. Zhong. 2017. Effects of lactic acid bacteria and molasses additives on the microbial community and fermentation quality of soybean silage. Bioresour. Technol. 238:706-715. doi:10.1016/j. biortech.2017.04.055

Nieves, D., O. Terán, L. Cruz, M. Mena, y F. Gutiérrez. 2011. Digestibilidad de nutrientes en follaje de arnica (Tithonia diversifolia) en conejos de engorde. Trop. Subtrop. Agroecosyst. 14:309-314.

Ojeniyi, O., S. Odedina, and T. Agbede. 2012. Soil productivity improving attributes of Mexican sunflower (Tithonia diversifolia) and siam weed (Chromolaena odorata). Emirates J. Food Agric. 24:243-247. 
Oliveira, A., A. Bagaldo, D. Loures, L. Bezerra, S. Moraes, S. Yamamoto, F. Araújo, L. Cirne, and L. Oliveira. 2018. Effect of ensiling gliricidia with cassava on silage quality, growth performance, digestibility, ingestive behavior and carcass traits in lambs. Anim. Feed Sci. Technol. 241:198-209. doi:10.1016/j.anifeedsci.2018.05.004

Oliveira, A.S., Z.G. Weinberg, I.M. Ogunade, A.A. Cervantes, K.G. Arriola, Y. Jiang, D. Kim, X. Li, M. Gonçalves, D. Vyas, and A. Adesogan. 2017. Meta-analysis of effects of inoculation with homofermentative and facultative heterofermentative lactic acid bacteria on silage fermentation, aerobic stability, and the performance of dairy cows. J. Dairy Sci. 100:45874603. doi:10.3168/jds.2016-11815

Palma, J. 2006. Los sistemas silvopastoriles en el trópico seco Mexicano. Arch. Latinoam. Prod. Anim. 14(3):95-104.

Parvin, S., N. Das, N. Jahan, M. Akhter, L. Nahar, and E. Islam. 2015. Evaluation of in vitro anti inflammatory and antibacterial potential of Crescentia cujete leaves and stem bark. BMC Res. Notes 8:412. doi:10.1186/s13104-015-1384-5

Pérez, A., I. Montejo, J.M. Iglesias, O. López, J.G. Martín, D.E. García, M. Idolkis, y A. Hernández. 2009. Tithonia diversifolia (Hemsl.) A. Gray. Pastos y Forrajes 32(1):1-15.

Puerto, E. 2012. Evaluación de tres especies con potencial forrajero del trópico alto y medio. Tesis grado, Universidad Nacional Abierta y a Distancia, Bogotá, COL.

Rincón, A. 2005. Ceba de bovinos en pasturas de Brachiaria decumbens suplementados con caña de azúcar y Cratylia argentea. Pasturas Trop. 27(1):2-12.

Ríos, C., y A. Salazar. 1995. Botón de oro (Tithonia diversifolia (Hemsl.) Gray) una fuente proteica alternativa para el trópico; (Primera parte). Livest. Res. Rural Dev. 6(3). http://www.lrrd.org/lrrd6/3/9.htm (consultado 29 mar. 2018).

Roa, M., y J. Galeano. 2015. Calidad nutricional y digestibilidad in situ de ensilajes de cuatro leñosas forrajeras. Pastos y Forrajes 38(4):431-440.

Roa, M., E. Ladino, y M. Hernández. 2017. Indicadores de bioquímica sanguínea en bovinos suplementados con Cratylia argentea y Saccharomyces cerevisiae. Pastos y Forrajes 40(2):144-151.

Rodríguez, G., y B. Roncallo. 2013. Producción de forraje y respuesta de cabras en crecimiento en arreglos silvopastoriles basados en Guazuma ulmifolia, Leucaena leucocephala y Crescentia cujete. Corpoica Cienc. Tecnol. Agropecu. 14(1):77-89.

Ruiz, T., G. Febles, J. Alons, G. Crespo, and N. Valenciaga. 2017. Agronomy of Tithonia diversifolia in Latin America and the Caribbean region. In: L. Savon et al., editors, Mulberry, moringa and tithonia in animal feed, and other uses. FAO, Rome, ITA. p. 171-201.

Ruiz, T., G. Febles, and H. Díaz. 2012. Plantation distance, frequency and cutting height on the biomass production of Tithonia diversifolia collection 10 during the year. Cuban J. Agric. Sci. 46:423-426.

Ruiz, T.E., GJ. Febles, JL. Galindo, L. Savón, B. Chongo, V. Torres, D. Cino, J. Alonso, Y. Martínez, D. Gutiérrez, GJ. Crespo, L. Mora, I. Scull, O. La, J. González, S. Lok, N. González, and A. Zamora. 2014. Tithonia diversifolia, its possibilities in cattle rearing systems. Rev. Cub. Cienc. Agric. 48(1):79-82.

Saavedra, S. 2016. Fenología y fisiología de las semillas de botón de oro Tithonia diversifolia (Hemsl.) Gray. Tesis MSc., Universidad Nacional Medellín, COL.

Sajani, J., and K. Sujatha. 2017. Antifeedant activity of different solvent extracts of Gliricidia sepium against third instar larvae of Helicoverpa armigera (Hubner) (Lepidoptera : Noctuidae). Int. J. Adv. Res. Biol. Sci. 4:201-204. doi:10.22192/ ijarbs.2017.04.04.026

Santos-da-Silva, W., T.M. Carvalho-dos-Santos, C.C. Cavalcanti-Neto, A.M Espíndola-Filho, S.G. Mesquita-da-Silva, A. Neves-Figueiredo, y B. Araújo-de-Melo. 2014. Características y estabilidad aeróbica de ensilajes de caña de azúcar, tratada con urea, NaOH y maíz. Pastos y Forrajes 37(2):182-190. 
Sarria, P. 1999. Forrajes arbóreos en la alimentación de monogástricos. FAO, Roma, ITA. http://www.fao.org/docrep/006/ Y4435S/y4435s0j.htm (consultado 22 mar. 2018).

Savón, L., L. Mora, L. Dihigo, and T. Ruiz. 2017. Use of Tithonia diversifolia in non-ruminants. In: L. Savon et al., editors, Mulberry, moringa and tithonia in animal feed, and other uses. FAO, Rome, ITA. p. 223-235.

Smethursta, P., N. Huth, P. Masikati, G. Sileshi, and F. Akinnifesie. 2017. Accurate crop yield predictions from modelling treecrop interactions in gliricidia-maize agroforestry. Agric. Syst. 155:70-77. doi:10.1016/j.agsy.2017.04.008

Solarte, L., E. Murgueitio, J. González, F. Uribe, y L. Manzano. 2013. Protocolo para la siembra de botón de oro y leucaena en potreros con praderas mejoradas para el establecimiento de sistemas silvopastoriles intensivos. FEDEGAN-SENA, Bogotá, COL.

Sossa, C., y R. Barahona. 2015. Comportamiento productivo de novillos pastoreando en trópico de altura con y sin suplementación energética. Rev. Med. Vet. Zootec. 62:67-80. doi:10.15446/rfmvz.v62n1.49386

Sotelo, M., J. Suárez, F. Álvarez, A. Castro, V. Calderón, y J. Arango. 2017. Sistemas sostenibles de producción ganadera en el contexto amazónico-Sistemas silvopastoriles: ¿una opción viable? Publicación No. 448. CIAT, Cali, COL.

Soto, S., J. Rodríguez, y R. Russo. 2009. Digestibilidad in vitro en forrajes tropicales a diferentes edades de rebrote. Tierra Trop. 5(1):83-89.

Stürm, C., T. Tiemann, C. Lascano, M. Kreuzer, and H. Hess. 2007. Nutrient composition and in vitro ruminal fermentation of tropical legume mixtures with contrasting tannin contents. Anim. Feed Sci. Technol. 138:29-46. doi:10.1016/j. anifeedsci.2006.11.008

Suárez, R., J. Mejía, M. González, D.E. García, y D.A. Perdomo. 2011. Evaluación de ensilajes mixtos de Saccharum officinarum y Gliricidia sepium con la utilización de aditivos. Pastos y Forrajes. 34(1):69-85.

Takemura, T., T. Kamo, E. Sakuno, S. Hiradate, and Y. Fujii. 2013. Discovery of coumarin as the predominant allelochemical in Gliricidia sepium. J. Trop. For. Sci. 25:268-272.

Tapasco, J., J. Martínez, S. Calderón, G. Romero, D.A. Ordóñez, A. Álvarez, L. Sánchez, y C. Ludeña. 2015. Impactos económicos del cambio climático en Colombia: sector ganadero. Banco Interamericano de Desarrollo, WA, USA. https:// publications.iadb.org/handle/11319/7186 (consultado 04 abr. 2018).

Valles de la Mora, B., E. Castillo, J. Jarillo, E. Ocaña, and M. Alonso. 2018. Development of Tropical Forages in Veracruz, Mexico: Agronomic Approach for the New Forage Legume Cratylia argentea. New Persp. Forage Crops 3:51-67. doi:10.5772/intechopen.69617

Vennila, C., S. Gunasekaran, and V. Sankaran. 2016. Effect of lopping interval on the growth and fodder yield of Gliricidia sepium. Agric. Sci. Digest. 36:228-230. doi:10.18805/asd.v36i3.11448

Verdecia, D., R. Herrera, J. Ramírez, I. Acosta, R. Bodas, S. Lorente, F. Giráldez, J. González, Y. Arceo, Y. Bazán, Y. Álvarez, y S. López. 2014. Caracterización bromatológica de seis especies forrajeras en el Valle del Cauto, Cuba. Avanc. Invest. Agropecu. 18(3):75-90.

Verdecia, D., J. Ramírez, I. Acosta, Y. Álvarez, Y. Bazán, R. Bodas, S. Lorente, J. Álvarez, F. Giráldez, y S. López. 2011. Calidad de la Tithonia diversifolia en una zona del Valle del Cauto. REDVET 12(5):1-13.

Von-Son-de-Fernex, E., M. Alonso-Díaz, B. Valles-de la Mora, P. Mendoza, E. Castillo, A. Zamilpa, and M. González. 2018. Effect of Gliricidia sepium leaves intake on larval establishment of Cooperia punctata in calves and bio-guided fractionation of bioactive molecules. Vet. Parasitol. 252:137-141. doi:10.1016/j.vetpar.2018.02.003

Zhao, G., Z. Xi, W. Chen, X. Li, L. Sun, and L. Sun. 2012. Chemical constituents from Tithonia diversifolia and their chemotaxonomic significance. Biochem. System. Ecol. 44:250-254. doi:10.1016/j.bse.2012.06.019 